\title{
OUVIDORIA: A IMPORTÂNCIA DA QUALIDADE PERCEBIDA COMO DIFERENCIAL ESTRATÉGICO
}

\section{Cristiane Hazin ${ }^{1}$}

\section{Resumo}

Este artigo apresenta um novo olhar dos clientes e empresários sobre a Ouvidoria. Sua importância estratégica para as instituições, seu papel de facilitador para os clientes e a inestimável contribuição que oferece por meio de proposituras de ações de melhorias que agradam não só aos clientes, mas também aos "Donos do Negócio", que percebem maior rentabilidade. Não há como esquecer o papel valioso desempenhado pelas Ouvidorias na mediação de conflitos, solucionando ou minimizando os danos, contribuindo para a redução da judicialização das demandas. Os hospitais, onde a percepção de qualidade alinhada à satisfação se apresenta de forma mais sutil, para se tornarem competitivos no mercado e oferecerem um diferencial de qualidade, têm buscado cada vez mais os selos de acreditação ou a introdução em programas de gestão de qualidade (ISO), e isto fez com que percebessem a necessidade de um setor apropriado para ouvir o cliente, uma vez que é ele, o cliente, o maior ativo de uma empresa e, portanto, uma valiosa fonte de informação que garantirá sua sustentabilidade. A metodologia aplicada para desenvolver este trabalho foi a Revisão Bibliográfica.

Palavras-chave: Ouvidoria. Rentabilidade. Conflitos. Qualidade. Satisfação.

1 Graduada em Fonoaudiologia pela Universidade Católica de Pernambuco e Pós-Graduada em Gestão de Ouvidorias pela Escola Superior de Relações Públicas. Certificada no Curso Oficial de Ouvidoria pela Associação Brasileira de Ouvidores - Seccional/ PE. Membro do Conselho de Ética da ABO Seccional/PE. Ouvidora do HOPE - Hospital de Olhos de Pernambuco. (crishazin@hotmail.com) 


\begin{abstract}
This article presents a new look of customers and businessmen about the Ombudsman's Office. Its strategic importance for the institutions, its facilitating role for the clients and the invaluable contribution that it offers through improvements actions that appeal not only to the clients, but also to the "Business Owners" who perceive greater profitability. There is no way to forget the valuable role played by the Ombudsman's Offices in the mediation of conflicts, solving or minimizing damages, contributing to the reduction of the judicialization of demands. Hospitals, where the perception of satisfaction-aligned quality presents itself more subtly, in order to become competitive in the market and offer a quality differential, have increasingly sought accreditation stamps or the introduction into quality management programs (ISO) and this made them realize the need for an appropriate sector to listen to the customer, since it is the customer the largest asset of a company and therefore a valuable source of information that will ensure its sustainability. The methodology applied to develop this work was the Bibliographic Review.
\end{abstract}

Keywords: Ombudsman. Profitability. Conflicts. Quality. Satisfaction. 


\section{INTRODUÇÃO}

As Ouvidorias surgiram em decorrência da necessidade de um elo imparcial entre o povo e o Estado. No Brasil, de acordo com VISMONA; BARREIRO, 2015, surgiram após o fim da ditadura, quando o povo castigado pela opressão gritava ansiosamente pela liberdade de expressão e manutenção de seus diretos. Tiveram como modelo o Ombudsman, termo sueco criado há mais de duzentos anos, e se fortaleceu com a Constituição Brasileira de 1988. Como grande marco, houve a criação do Código de Defesa do Consumidor - CDC, em 1990 (GUIA DE OUVIDORIAS BRASIL, 2011). A partir desse ponto, as Ouvidorias ganharam nova dimensão, visto que o CDC trouxe luz para o cliente sobre seus direitos e orientações de como agir na hipótese desses direitos serem frustrados.

Hoje, embora instrumento de grande potencial, ainda são pouco difundidas entre as empresas privadas. As Ouvidorias atuam obrigatoriamente na esfera do Poder Público e nas instituições financeiras e operadoras de planos de saúde. Apenas nos últimos anos as instituições privadas, com a busca pelos selos de acreditação e com a percepção de que qualidade alinhada à satisfação do cliente permite torná-las mais competitivas no mercado, começaram a implantar o setor de Ouvidoria como um diferencial de qualidade. Quando esse setor existe e é bem sedimentado dentro da empresa, ou seja, representa o canal direto do cliente com a alta administração, ele favorece a captação de novos clientes e a qualidade é reforçada por meio de processos mais seguros entre os departamentos da empresa, seja ela um hospital ou outro segmento empresarial.

Para garantir o êxito da Ouvidoria dentro da instituição, é indispensável que ela conte com o total apoio da alta direção. Por isso é importante uma contratação criteriosa, a fim de assegurar que o futuro Ouvidor tenha os requisitos necessários para exercer a atividade. $\mathrm{O}$ apoio expressamente difundido, a independência hierárquica, bem como o empoderamento do Ouvidor são primordiais para o êxito dessa função.

O grande desafio deste trabalho, desenvolvido por meio de Revisão Bibliográfica, é despertar, principalmente nos dirigentes de instituições privadas, o entendimento da substancial importância que a Ouvidoria exerce para a sustentabilidade de seu negócio. O cliente, sentindo-se acolhido e percebendo a preocupação da instituição com seu bem-estar e o interesse em atender às suas expectativas, será o maior propagador das experiências de sucesso vivenciadas nessa instituição, e com isso novos clientes serão atraídos, contribuindo para o crescimento econômico da empresa.

\section{OUVIDORIA PRIVADA - SATISFAÇÃO QUE GERA LUCRO}

O sentimento de impor as normas e ter a certeza de que o cliente somente tem que acatá-las está ficando cada vez mais para trás. Hoje, é o cliente quem dita as normas. É ele quem diz como quer ser atendido e o que espera das instituições. Ciente do poder que detém, está cada vez mais exigente e, portanto, obrigando as instituições que desejam prosperar no mercado competitivo a buscar a excelência no serviço prestado.

Com todas essas transformações, surgem no mercado diversas empresas que se propõem 
a avaliar as instituições privadas e classificá-las como detentoras de certificações de qualidade. Tudo isso é muito positivo, principalmente para o cliente, visto que promove maior segurança nos processos e qualidade do serviço prestado. Contudo, este valor nem sempre é percebido por ele, que avalia o serviço conforme a entrega realizada, ou seja, se sua expectativa foi ou não atendida. Dessa forma, é fundamental que exista uma comunicação efetiva e uma disseminação da certificação alcançada, esclarecendo todos os benefícios e valores que ela agrega ao serviço e consequentemente ao cliente.

De acordo com TOTAL GESTÃO (apud Rangel, 1994), "As pessoas contam suas experiências ruins para dez outras; as experiências positivas são contadas para apenas cinco".

A citação acima já não faz mais sentido nos dias atuais. Com o advento da internet e das redes sociais, milhares de informações são difundidas em segundos e, embora este tenha sido um ganho imensurável para a sociedade, também representa um grande pesadelo para as instituições, que se veem expostas por qualquer deslize cometido ou mesmo pela percepção negativa do cliente. Por outro lado, a internet tornou-se ferramenta bastante poderosa utilizada pelos consumidores, já que, a fim de evitar exposição danosa, as empresas estão aprimorando cada vez mais o serviço prestado e entendendo a importância de ouvir o seu cliente.

A Ouvidoria privada entra nesse cenário como ferramenta de gestão, pois, detentora dos objetivos estratégicos da empresa, entende ser o cliente o maior ativo gerador de lucro. Se por um lado a Ouvidoria ajuda a instituição na obtenção de lucros e na melhoria de seus processos, por outro promove para o cliente a certeza de um serviço seguro e de qualidade, estabelecendo uma relação de equilíbrio entre as partes.

Dessa forma, munidos de qualidade total por meio de um olhar crítico sobre a instituição, será entendido que o retorno financeiro está diretamente ligado à qualidade percebida pelo cliente, e isso somente acontecerá com a mudança de paradigma, conquistada por meio da atuação da Ouvidoria no entendimento das necessidades e expectativas dos clientes, alinhada aos valores da instituição bem como ao comprometimento e parceria de todos os setores.

\subsection{Ouvidoria como Diferencial Competitivo}

É fato que com o crescimento populacional também há o crescimento na oferta de serviços e produtos, o que gera disputa pela maior fatia de mercado entre as empresas. É necessário inovar, proporcionar preços atrativos, serviços de qualidade e acima de tudo, para sobreviver no mercado atual, é preciso fidelizar o cliente. Fazer com que a experiência dele ao utilizar o serviço ou adquirir um produto seja tão extraordinária que não reste um espaço sequer para dúvidas e que ele ainda propague com a mesma abrangência virtual a satisfação plena percebida no serviço prestado.

A ferramenta para conduzir a esse objetivo é a Ouvidoria. O caminho inicial a ser trilhado é entender os valores da instituição, conhecer o perfil dos clientes externos e internos. No caso destes últimos, é fundamental uma parceria com o setor de Recursos Humanos da empresa para entender se os valores dos colaboradores estão alinhados com os da instituição, caso contrário será impossível a conquista do objetivo traçado. 
Manter clientes após a realização da primeira venda tem se tornado cada vez mais importante e desafiante; a acirrada competição tem feito com que muitos clientes passem a ser ao mesmo tempo mais exigentes e menos leais. À medida que produtos e clientes vão ficando mais sofisticados, produtores e fornecedores competem em serviço e qualidade, bem como em termos de características, preço e prazos de entrega do produto. Felizmente, as novas tecnologias também têm permitido que as empresas possam fazer um acompanhamento mais direto das necessidades de seus clientes, podendo desenvolver operações mais eficientes visando satisfazer a tais necessidades. (SVIOKLA, 1994)

A Ouvidoria por meio das informações dos clientes produzirá insumos valiosos para a alta gestão da instituição, uma vez que a análise de desempenho sob a perspectiva do cliente poderá indicar decisões tanto estratégicas como operacionais que influenciem a qualidade dos serviços prestados.

De acordo com SAMPAIO, 2018 (apud ARAÚJO, 2001),

As organizações que não se preocupam em agradar seus clientes têm a própria existência ameaçada, porque altos lucros estão mais correlacionados com a melhor qualidade percebida pelo cliente do que com a participação de mercado ou qualquer outra variável. Essa chamada de retorno ao cliente como principal centro de atenção da qualidade, em conjunto com a certeza cada vez mais forte de que, em qualquer que seja a organização, mesmo nas indústrias, sempre haverá um momento de prestação de serviço, foi o fator que trouxe a qualidade em serviços à esfera de discussões no mundo dos executivos de primeiríssima linha.

Hoje, muitos modelos de pesquisas são divulgados com a proposta de entregar aos gestores o caminho para a conquista dos clientes, entendendo o que eles esperam do serviço ofertado e que os fazem felizes. O mais importante, porém, não é a quantidade de pesquisas realizadas, mas o que é feito com todas as informações coletadas nessas pesquisas. Quais ações de melhorias estão verdadeiramente sendo implantadas e qual o comprometimento de todos da instituição, viabilizando a implantação dessas ações. Somente com o entendimento e engajamento de todos é que os dados obtidos por meio das pesquisas realizadas serão transformados em informações que irão contribuir com o aumento da rentabilidade por meio da efetiva satisfação.

A gama de insumos produzidos através das pesquisas e relatos dos clientes nos permite construir relacionamentos. Assim, as empresas devem buscar na satisfação uma forma de fidelizar o cliente e estreitar essa relação, tornando-os parceiros do negócio. Esse é o diferencial.

Estamos vivendo a era do empoderamento do consumidor. Estamos migrando da era do "prazer em ter" para o "prazer em experimentar", e ele quer resultado além da expectativa.

O risco das empresas ao interpretarem a satisfação de seus clientes tomando por base a qualidade está no fato de que os aspectos atinentes à qualidade são determinados, normalmente, pela percepção dos gerentes, ressaltando que, em muitos casos, tal entendimento pode diferir totalmente da visão dos clientes. (MILAN; TREZ, 2005, apud ZEITHAML; BERRY; PARASURAMAN, 1988)

Conhecer o cliente e entender sua expectativa é fazer dele seu maior aliado. O relacionamento instituição-cliente deve ser construído a todo o momento com transparência e integridade. Para tanto, é necessário muitas vezes que a instituição tenha a disposição de ceder diante de um 
conflito. Essa perda aparente resultará mais adiante como diferencial de escolha para aquele cliente que vivenciou a conduta ética e despretensiosa da empresa. Está estabelecida uma conexão emocional. Ao entender o que é importante para o cliente, a instituição estabelece uma relação de empatia que, bem administrada, permitirá a obtenção de informações valiosas que trarão grande contribuição competitiva.

\section{CONSIDERAÇÕES FINAIS}

Quando se oferece a possibilidade de ouvir de verdade aquele que se utiliza e se beneficia do serviço de uma instituição, a questão vai além do ditado que afirma que "o cliente tem sempre razão". O cliente é a razão do negócio. Se existe ou não procedência nesta ou naquela queixa específica não é importante. O que vale é a sensibilidade para entender que, por trás da queixa realizada, existe uma expectativa não alcançada. O diferencial estará na instituição que perceber a Ouvidoria como um tesouro de informações trazidas pelo seu ativo mais importante - o Cliente.

Proporcionar um serviço impecável com praticamente erro zero só será possível com o entendimento dos pontos fortes e fracos da instituição e com a disseminação de sua cultura, gerando a participação efetiva de todos os membros, com foco na qualidade e no serviço ao cliente (SAMPAIO, 2018).

Acreditar que proporcionar satisfação aos clientes irá garantir obrigatoriamente sua fidelização é irreal. De acordo com REICHHELD (1993), pesquisas já demonstram que $65 \%$ a $85 \%$ dos clientes que trocaram de fornecedor disseram que estavam satisfeitos com o fornecedor antigo. No entanto, entender o que estimula a satisfação do cliente e investir para torná-la real irá contribuir fortemente para transformar esta satisfação em lealdade (MILAN; TREZ, 2005, apud OLIVER, 1999).

Assim, é preciso entender que a Ouvidoria é um poderoso instrumento de gestão pelo fato de funcionar com a participação efetiva de quem consome o serviço. Consequentemente, uma ferramenta essencial para a transformação institucional, favorecendo mudanças e ajustes nas atividades e processos, quebrando paradigmas e promovendo o engajamento de toda a instituição, transformando situações conflituosas em relações harmônicas e contribuindo para o aprimoramento contínuo do serviço oferecido.

\section{REFERÊNCIAS}

GUIA DE OUVIDORIAS DO BRASIL. São Paulo: Padrão Editorial, 2011.

MILAN, Gabriel Sperandio; TREZ, Guilherme. Pesquisa de satisfação: um modelo para planos de saúde. Disponível em: < http://www.scielo.br/pdf/raeel/v4n2/v4n2a02.pdf>. Acesso em: 22 maio 2018.

SAMPAIO, José Roberto Tavares. Seis Sigma: a qualidade percebida. Disponível em: <http://www.administradores. com.br/artigos/marketing/seis-sigma-a-qualidade-percebida/20187/>. Acesso em: 29 maio 2018.

SVIOKLA, John J.; SHAPIRO, Benson P. Mantendo clientes. São Paulo: Makron Books, 1994.

TOTAL GESTÃO. Satisfação dos Clientes: a garantia da continuidade do seu negócio. Disponível em: <http://www. totalgestao.com.br/site/2013/04/satisfacao-dos-clientes-a-garantia-da-continuidade-do-seu-negocio/>. Acesso em: 14 maio 2018

VISMONA, E. L.; BARREIRO, A. E. A. Ouvidoria brasileira - o cidadão e as instituições: edição comemorativa, 20 anos da ABO. São Paulo: Associação Brasileira de Ouvidores, 2015. 